\title{
Postural Evaluation in a Poultry Farm for Broiler Chickens
}

\author{
Hui Wang \\ Industrial and Information Systems Engineering, Ajou University, Suwon, Korea \\ Yong-Ku Kong \\ Systems Management Engineering, Sungkyunkwan University, Suwon, Korea \\ Myung-Chul Jung \\ Industrial and Information Systems Engineering, Ajou University, Suwon, Korea
}

The goal of this study was to evaluate working postures in 9 operations of poultry farming for broiler chickens for 14 body segments with 4 categories, and for fingers with 14 categories. Overall, the farmers commonly bent almost all their body segments and used power grips. The operations of cleaning with water wand and inspecting chickens seemed light work because the farmers walked around most of their working time. The operations of detaching base from hanging feeder and attaching base to hanging feeder had the farmers continue squatting to handle the feeders close to the floor. The farmers also repeatedly bent their trunks in shoveling feces, unloading a box of chicks, and releasing chicks. A power grip was frequently observed due to using tools with round handles. Workplace design to raise working height would be necessary for a better working environment for broiler farmers.

simultaneous posture individual posture body posture finger posture

\section{INTRODUCTION}

Agriculture has been considered a hazardous industry due to the physically demanding manual material handling [1, 2, 3]. Even though automation has proliferated in recent years, manual material handling is still common in agriculture. Many studies have identified its association with work-related musculoskeletal disorders (MSDs) in various kinds of agricultural work, such as a dairy farm $[4,5,6,7,8,9,10,11,12,13]$, a swinery $[14,15,16]$, a poultry farm $[17,18,19]$, rice cultivation [20], and a pear and apple orchard [21]. These studies have confirmed that static awkward postures and repetitive movements of certain body segments are the risk factors of MSDs.

Work on a dairy farm, especially in a milking operation in a traditional tie stall, is associated with awkward postures and movements [7, 13]. After an automatic parlor milking system is introduced, however, a dairy farmer's physical burden is generally reduced with respect to heart rate, working posture, and perceived exertion [9]. Nevala-Puranen, Kallionpää, and Ojanen reported that a dairy farmer worked with the back in a neutral position for $85 \%$ of the milking time in a parlor [8]. The new system is better for the back but not for the upper extremities because of the raised working height $[10,12,13]$. Nevala-

This research was supported by Basic Science Research Program through the National Research Foundation of Korea (NRF) funded by the Ministry of Education, Science and Technology (2009-0070837).

Correspondence and requests for offprints should be sent to Myung-Chul Jung, Industrial and Information Systems Engineering, Ajou University, Suwon, 443-749, Republic of Korea. E-mail: mcjung@ajou.ac.kr. 
Puranen et al. found that a dairy farmer positioned the arms above the shoulder level for $24 \%$ of the milking time in a parlor, compared to $18 \%$ in a tie stall. Pinzke, Stål, and Hansson also found that the operations of drying the cow's udder, milking the first milk (premilking), and attaching the milking unit to the udder were stressful to the hand and wrist for female workers [10].

Work in a swinery is considered as strenuous as work on a dairy farm. The operations that require prolonged static postures and repetitive movements for several hours a day could be the main cause of work load resulting in MSDs in a swinery [16]. Geng and Torén reported that the feeding and watering operations contributed to pig farmers' high risk of accidents and high physical load [15]. Christensen, Vinzents, Nielsen, et al. also found that extensive manual material handling with awkward working postures possibly explained a high degree of low back pain among Danish pig farmers [14].

Although there is extensive research on agriculture and stockbreeding, very few studies compare poultry and dairy farms. Lundqvist reported that the accident rate on a poultry farm, partly resulting from overexertion of body segments and back injury from manual material handling, was two times higher than that on general farms [18]. Using the OVAKO working posture analysing system (OWAS) [22], Scott and Lambe found that collecting floor eggs and reaching into the perches caused a stockman to experience physical discomfort and strain [19]. They suggested perchery modification and mechanical egg collection for better working postures. Lee and Lee used the revised NIOSH (National Institute for Occupational Safety and Health) lifting equation [23], rapid entire body assessment (REBA) [24], and OWAS for MSD prevention on a chicken farm in Korea [17]. They found that most operations of mixing feeds, picking eggs, moving eggs, and throwing away feces caused stress or strain in the arm, trunk, shoulder, and knee because of inappropriate working height and heavy load.

Poultry farms for broilers, i.e., chickens raised for meat production, are generally mass-production farms with intensive farming techniques. However, their ergonomics have not been studied in contrast to farms for egg-laying hens. Since broilers and egg-laying hens are raised in different facilities, it is anticipated that broiler farmers require different working postures. Thus, the goal of this study was to evaluate the working postures of broiler farmers, who do most operations manually.

\section{METHODS}

\subsection{Poultry Farming Operations}

Unlike egg-laying hens housed in battery cages, tens of thousands of broilers are freely raised in a crowed shed on the floor covered with litter such as rice hulls. Broiler farming consists of 11 operations, but this study considered only 9 because the operation of removing feces following (3) shoveling feces did not involve any manual work (the farmer used an agricultural motor tractor), and feeding following (7) releasing chicks was not videotaped unfortunately (Table 1).

The farmer took the base off a hanging feeder, dumped feed remaining on the base to the floor, and placed the base on the floor in the operation of (1) detaching base from hanging feeder. There were $\sim 100$ hanging feeders. The famer carried a high-pressure sprayer and washed the inside of the shed in (2) cleaning with water wand. The farmer removed feces with a shovel in the corners in (3) shoveling feces. The farmer spread rice hulls on the entire floor with a broom in (4) spreading rice hulls. The farmer returned the base to the hanging feeder with a nut in (5) attaching base to hanging feeder. The farmer unloaded a box of chicks from a cart on the floor in (6) unloading a box of chicks. Each box contained 103 chicks. The farmer set chicks free on the floor by tilting the box in (7) releasing chicks. The farmer walked around watching chickens in (8) inspecting chickens. The farmer caught four chickens with each hand, carried them to crates on a truck, and tossed them one by one into open crates in (9) loading chickens into crates.

\subsection{Postural Evaluations}

Many postural analysis checklists have been proposed for evaluating body posturess or move- 


\begin{tabular}{|c|c|c|c|}
\hline \multirow[b]{2}{*}{ Operation } & \multirow[b]{2}{*}{ Sampling Time (s) (\%) } & \multicolumn{2}{|c|}{$\begin{array}{c}\text { No. of Simultaneous } \\
\text { Postures }\end{array}$} \\
\hline & & Body & Fingers \\
\hline (1) Detaching base from hanging feeder & $11.0(6.9)$ & 15 & 5 \\
\hline (2) Cleaning with water wand & $15.1 \quad(9.5)$ & 1 & 1 \\
\hline (3) Shoveling feces & $15.1 \quad(9.5)$ & 29 & 1 \\
\hline (4) Spreading rice hulls & $15.0(9.4)$ & 151 & 1 \\
\hline (5) Attaching base to hanging feeder & $31.7(19.8)$ & 15 & 7 \\
\hline (6) Unloading a box of chicks & $26.6(16.7)$ & 175 & 28 \\
\hline (7) Releasing chicks & $15.0(9.4)$ & 56 & 12 \\
\hline (8) Inspecting chickens & $15.0(9.4)$ & 38 & 1 \\
\hline (9) Loading chickens into crates & $15.0(9.4)$ & 21 & 5 \\
\hline total & $159.5(100)$ & 368 & 11 \\
\hline
\end{tabular}

Notes. The total number of simultaneous postures was counted only once for the same posture across the tasks.

ments such as Armstrong, Foulke, Joseph, et al. [25], Keyserling [26], REBA [24], RULA [27], and OWAS [22]. On the basis of the checklists, Hwang, Kong, and Jung developed body and finger classifications for evaluating working postures in dairy farms [6]. Wang, Hwang, Lee, et al. also adopted the classifications to evaluate upper body and finger postures in the whole process in an electric iron assembly plant [28].

Unlike the other checklists, Hwang et al. used only terms of 14 body segments instead of mixing the terms of segments and joints to keep terminology consistent [6] (Table 2). Each body segment had 3 or 4 categories of neutral $(\mathrm{N})$,

TABLE 2. Body Posture Classification [6]

\begin{tabular}{lcccc}
\hline Segment & \multicolumn{4}{c}{ Classification } \\
\hline Head (H) & N & B & T & I \\
Right upper arm (RUA) & N & B & & I \\
Left upper arm (LUA) & N & B & & I \\
Right lower arm (RLA) & N & B & & I \\
Left lower arm (LLA) & N & B & & I \\
Right hand (RH) & N & B & T & I \\
Left hand (LH) & N & B & T & I \\
Trunk (Tr) & N & B & T & I \\
Right upper leg (RUL) & N & B & & I \\
Left upper leg (LUL) & N & B & & I \\
Right lower leg (RLL) & N & B & & I \\
Left lower leg (LLL) & N & B & & I \\
Right foot (RT) & N & B & T & I \\
Left foot (LT) & N & B & T & I \\
\hline
\end{tabular}

Notes. N-neutral, B-bend, T-twist, l-invisible. bend (B), twist (T), and invisible (I). Neutral was $0^{\circ}$ of a segment with respect to the line of gravity. Bend was deviation from $0^{\circ}$ in any direction. Twist was a rotation along the long axis of a segment. The category of invisible applied to all segments whenever the segments could not be observed. Finger postures contained 14 classifications to represent a hand coupling with objects or tools, including invisible (Table 3).

The working postures of 5 farmers were videotaped while they performed normal duties in the farm. They were analyzed with the body and finger classifications. The camera angle was carefully chosen so that the segments of interest were captured on video. Postural analyses were done in the laboratory by a skilled observer who had participated in the development of the classifications. Like in Keyserling's evaluation method [26], the observer played and stopped the video to record working durations and postures whenever farmers changed their postures. The observer used the classification codes of $\mathrm{N}, \mathrm{B}$, $\mathrm{T}$, and I for body segments (Table 2) and resting (R), palm touch (PT), tip touch (TT), palm wrap $(\mathrm{PW})$, 1-finger wrap (1W), 2-finger wrap (2W), 3-finger wrap (3W), 4-finger wrap (4W), 5-finger wrap $(5 \mathrm{~W}), 2$-finger pinch (2P), 3-finger pinch (3P), 4-finger pinch (4P), 5-finger pinch (5P), and I for fingers (Table 3). Then, the most common simultaneous postures and individual postures in terms of working times were collected for the body and fingers in each operation and for overall operations. The most common simulta- 
TABLE 3. Finger Posture Classification [6]

\begin{tabular}{ll}
\hline Classification & \multicolumn{1}{c}{ Definition } \\
\hline Resting (R) & The fingers and the palm are relaxed, no activity is performed. \\
Palm touch (PT) & The palm with or without the fingers touches one side of an object. \\
Tip touch (TT) & The finger tip touches a side of an object. \\
Palm wrap (PW) & The palm only folds round an object. \\
1-finger wrap (1W) & One finger with or without the palm folds round an object. \\
2-finger wrap (2W) & Two fingers with or without the palm fold round an object. \\
3-finger wrap (3W) & Three fingers with or without the palm fold round an object. \\
4-finger wrap (4W) & Four fingers with or without the palm fold round an object. \\
5-finger wrap (5W) & Five fingers with or without the palm fold round an object. \\
2-finger pinch (2P) & Two fingertips grasp an object from opposite sides. \\
3-finger pinch (3P) & Three fingertips grasp an object from opposite sides. \\
4-finger pinch (4P) & Four fingertips grasp an object from opposite sides. \\
5-finger pinch (5P) & Five fingertips grasp an object from opposite sides. \\
Invisible (l) & Posture cannot be observed. \\
\hline
\end{tabular}

neous posture represented the posture that had the longest working time among the postures the farmer took concurrently for all 14 segments. The most common individual posture represented the posture of each segment that had the longest time, considering 14 segments separately. The same concept was used for the right and left fingers for the common simultaneous and individual finger postures.

\section{RESULTS}

\subsection{Common Simultaneous Postures}

Overall, the operations on a poultry farm for broilers required 368 different simultaneous body postures and 11 different simultaneous finger postures (Table 1). Bending all 14 body segments at the same time was the most common simultaneous body posture (Table 4). It took $17.3 \%$ $(27.6 / 159.5 \mathrm{~s})$ of the total sampling time. The most common simultaneous body posture of each operation appeared similar to that in overall operations, but had somewhat different characteristics of working postures in certain body segments. Operation (8) inspecting chickens used the neutral upper and lower arms in 5.6\% (0.84/15 s) of the sampling time instead of bending the arms because the farmer was just walking around the shed. In (2) cleaning with water wand and (9) loading chickens into crates the farmers had the neutral upper and lower legs because they were standing most of the working time. Thus, the trunk was also in a neutral posture in (2) cleaning with water wand and (8) inspecting chickens. The percentage of the simultaneous body postures in the sampling time of each operation ranged from $7.2 \%$ (1.9/26.6 s) for (6) unloading a box of chicks to $100 \%(15.1 / 15.1 \mathrm{~s})$ for $(2)$ cleaning with water wand.

The most common simultaneous posture of the right and left fingers was that of all fingers wrapped around an object (a power grip) $\sim 52.2 \%(83.2 / 159.5 \mathrm{~s})$ of the total sampling time (Table 5). The same posture was observed in most operations of (2) cleaning with water wand, (3) shoveling feces, (4) spreading rice hulls, (6) unloading a box of chicks, (7) releasing chicks, and (9) loading chickens into crates because the farmers held the corresponding tools or materials (i.e., water wand, shovel, broom, box, and chick).

\subsection{Common Individual Postures}

The most common individual posture of each body segment was different from the most common simultaneous posture only in a few body segments, usually in the legs and feet, in most operations, but it was exactly same in overall operations, (1) detaching base from hanging feeder, (2) cleaning with water wand, (5) attaching base to hanging feeder, and (8) 
TABLE 4. Common Simultaneous Body Postures

\begin{tabular}{|c|c|c|c|c|c|c|c|c|c|c|}
\hline \multirow[b]{2}{*}{ Segment } & \multicolumn{10}{|c|}{ Operation } \\
\hline & Overall & 1 & 2 & 3 & 4 & 5 & 6 & 7 & 8 & 9 \\
\hline $\mathrm{H}$ & B & $\mathrm{N}$ & $\mathrm{N}$ & B & $B$ & B & $B \& T$ & B & B & $B \& T$ \\
\hline RUA & $B$ & $B$ & $\mathrm{~N}$ & B & $B$ & B & $B$ & $B$ & $\mathrm{~N}$ & B \\
\hline LUA & B & B & $\mathrm{N}$ & B & $B$ & B & B & B & $\mathrm{N}$ & B \\
\hline RLA & B & B & B & B & $B$ & B & B & B & $\mathrm{N}$ & B \\
\hline LLA & B & B & B & B & $B$ & B & B & B & $\mathrm{N}$ & B \\
\hline $\mathrm{RH}$ & B & I & B & $\mathrm{T}$ & $\mathrm{N}$ & B & B & B & $\mathrm{N}$ & B \\
\hline LH & B & $\mathrm{N}$ & $\mathrm{T}$ & $\mathrm{N}$ & $\mathrm{N}$ & B & B & B & $\mathrm{N}$ & B \\
\hline $\mathrm{Tr}$ & B & $B \& T$ & $\mathrm{~N}$ & B & $B$ & B & $B \& T$ & B & $\mathrm{N}$ & $B \& T$ \\
\hline RUL & $B$ & $B$ & $\mathrm{~N}$ & $B$ & $B$ & $B$ & $B$ & $B$ & $B$ & $\mathrm{~N}$ \\
\hline LUL & $B$ & $B$ & $\mathrm{~N}$ & $B$ & $B$ & $B$ & $B$ & $B$ & $B$ & $\mathrm{~N}$ \\
\hline RLL & B & B & $\mathrm{N}$ & B & $\mathrm{N}$ & B & B & B & B & $\mathrm{N}$ \\
\hline LLL & B & B & $\mathrm{N}$ & B & $B$ & B & B & B & B & $\mathrm{N}$ \\
\hline $\mathrm{RF}$ & B & B & 1 & B & $\mathrm{N}$ & B & B & $\mathrm{N}$ & $\mathrm{N}$ & $\mathrm{N}$ \\
\hline LF & $B$ & $B$ & 1 & $\mathrm{~N}$ & B & B & B & B & $B$ & $\mathrm{~N}$ \\
\hline$\%$ & 17.3 & 65.8 & 100 & 13.0 & 8.9 & 85.1 & 7.3 & 14.9 & 52.0 & 12.2 \\
\hline
\end{tabular}

Notes. 1-detaching base from hanging feeder, 2-cleaning with water wand, 3-shoveling feces, 4spreading rice hulls, 5-attaching base to hanging feeder, 6-unloading a box of chicks, 7 -releasing chicks, 8-inspecting chickens, 9-loading chickens into crates, $\mathrm{N}$-neutral, $\mathrm{B}$-bend, T-twist, l-invisible; the segments are defined in Table 2.

TABLE 5. Common Simultaneous Finger Postures

\begin{tabular}{|c|c|c|c|c|c|c|c|c|c|c|}
\hline \multirow[b]{2}{*}{ Finger } & \multicolumn{10}{|c|}{ Operation } \\
\hline & Overall & 1 & 2 & 3 & 4 & 5 & 6 & 7 & 8 & 9 \\
\hline Right & $5 W$ & I & $5 W$ & $5 W$ & $5 W$ & $3 P$ & $5 W$ & $5 W$ & $\mathrm{R}$ & $5 W$ \\
\hline Left & $5 W$ & $5 W$ & $5 W$ & $5 W$ & $5 W$ & $5 W$ & $5 W$ & $5 W$ & $\mathrm{R}$ & $5 W$ \\
\hline$\%$ & 52.2 & 74.8 & 100 & 100 & 100 & 65.2 & 43.1 & 67.6 & 100 & 46.9 \\
\hline
\end{tabular}

Notes. 1-detaching base from hanging feeder, 2-cleaning with water wand, 3-shoveling feces, 4spreading rice hulls, 5-attaching base to hanging feeder, 6-unloading a box of chicks, 7 -releasing chicks, 8-inspecting chickens, 9-loading chickens into crates, 5W-5-finger wrap, I-invisible, 3P-3-figer pinch, R-resting.

inspecting chickens (Table 6). All body segments bent in overall operations, and the postures took from $46.4 \%(74.0 / 159.5 \mathrm{~s})$ of the total sampling time for the left hand to $85.4 \%(136.2 / 159.5 \mathrm{~s})$ of the total sampling time for the right lower arm. Similarly to the results of the simultaneous body postures, (2) cleaning with water wand, (8) inspecting chickens, and (9) loading chickens into crates had either neutral arms or neutral legs.
The most common individual finger posture was the same as the most common simultaneous finger posture in all operations except (6) unloading a box of chicks (Table 7). The posture of $5 \mathrm{~W}$ (power grip) was the most common one for both right and left finger postures. It was overall $\sim 58.1 \%(92.7 / 159.5 \mathrm{~s})$ for the right fingers and $69.7 \%(111.2 / 159.5 \mathrm{~s})$ for the left fingers. 
TABLE 6. Common Individual Body Postures

\begin{tabular}{|c|c|c|c|c|c|c|c|c|c|c|}
\hline \multirow[b]{2}{*}{ Segment } & \multicolumn{10}{|c|}{ Operation } \\
\hline & Overall & 1 & 2 & 3 & 4 & 5 & 6 & 7 & 8 & 9 \\
\hline $\mathrm{H}$ & $B$ & $\mathrm{~N}$ & $\mathrm{~N}$ & $B$ & $B$ & $B$ & $\mathrm{~T}$ & $B$ & $B$ & B\&T \\
\hline$\%$ & 55.4 & 100 & 100 & 100 & 100 & 92.6 & 45.5 & 78.2 & 100 & 70.4 \\
\hline RUA & $B$ & $B$ & $\mathrm{~N}$ & B & $B$ & $B$ & $B$ & $B$ & $\mathrm{~N}$ & $B$ \\
\hline$\%$ & 68.1 & 100 & 100 & 69.8 & 88.9 & 100 & 83.0 & 63.8 & 100 & 69.6 \\
\hline LUA & B & B & $\mathrm{N}$ & B & B & B & B & B & $\mathrm{N}$ & B \\
\hline$\%$ & 69.9 & 100 & 100 & 100 & 86.0 & 100 & 79.2 & 59.1 & 100 & 72.4 \\
\hline$R L A$ & B & B & B & B & B & B & B & $B$ & $\mathrm{~N}$ & B \\
\hline$\%$ & 85.4 & 87.9 & 100 & 100 & 100 & 91.7 & 84.5 & 98.4 & 100 & 100 \\
\hline LLA & $B$ & $B$ & $B$ & $B$ & $B$ & B & B & B & $\mathrm{N}$ & $B$ \\
\hline$\%$ & 80.8 & 86.1 & 100 & 100 & 54.9 & 95.2 & 83.2 & 98.4 & 100 & 92.9 \\
\hline $\mathrm{RH}$ & $B$ & I & $B$ & $\mathrm{~T}$ & $\mathrm{~N}$ & $B$ & $B$ & $B$ & $\mathrm{~N}$ & $B$ \\
\hline$\%$ & 50.5 & 68.2 & 100 & 100 & 100 & 85.2 & 69.9 & 74.2 & 100 & 57.8 \\
\hline LH & $B$ & $\mathrm{~N}$ & $\mathrm{~T}$ & $\mathrm{~N}$ & $\mathrm{~N}$ & $B$ & $B$ & $B$ & $\mathrm{~N}$ & $B$ \\
\hline$\%$ & 46.4 & 89.4 & 100 & 100 & 65.1 & 92.7 & 56.0 & 89.6 & 100 & 63.3 \\
\hline $\operatorname{Tr}$ & B & $B \& T$ & $\mathrm{~N}$ & $B$ & $B$ & $B$ & B\&T & $B$ & $\mathrm{~N}$ & $\mathrm{~N}$ \\
\hline$\%$ & 49.1 & 83.9 & 100 & 100 & 100 & 100 & 56.6 & 86.2 & 100 & 40.9 \\
\hline RUL & B & B & $\mathrm{N}$ & $\mathrm{N}$ & B & B & $\mathrm{N}$ & $B$ & B & $\mathrm{N}$ \\
\hline$\%$ & 62.0 & 100 & 100 & 55.2 & 91.6 & 94.1 & 50.8 & 62.7 & 100 & 100 \\
\hline LUL & B & B & $\mathrm{N}$ & $\mathrm{N}$ & B & B & B & B & B & $\mathrm{N}$ \\
\hline$\%$ & 60.9 & 100 & 100 & 54.5 & 80.7 & 94.1 & 50.9 & 59.1 & 100 & 100 \\
\hline RLL & B & B & $\mathrm{N}$ & B & $\mathrm{N}$ & B & $\mathrm{N}$ & B & B & $\mathrm{N}$ \\
\hline$\%$ & 58.0 & 100 & 100 & 68.4 & 74.9 & 94.1 & 50.8 & 62.7 & 100 & 100 \\
\hline LLL & B & B & $\mathrm{N}$ & $\mathrm{N}$ & $\mathrm{N}$ & B & B & B & B & $\mathrm{N}$ \\
\hline$\%$ & 56.3 & 100 & 100 & 62.3 & 59.8 & 94.1 & 50.0 & 59.3 & 100 & 100 \\
\hline RF & B & B & I & B & I & B & $\mathrm{N}$ & $\mathrm{N}$ & $\mathrm{N}$ & $\mathrm{N}$ \\
\hline$\%$ & 49.6 & 92.4 & 100 & 57.2 & 40.4 & 94.1 & 55.0 & 58.7 & 53.3 & 100 \\
\hline LF & $B$ & $B$ & I & $\mathrm{N}$ & I & B & B & $\mathrm{N}$ & B & $\mathrm{N}$ \\
\hline$\%$ & 52.2 & 96.7 & 100 & 70.0 & 40.4 & 94.1 & 65.8 & 53.3 & 57.6 & 100 \\
\hline
\end{tabular}

Notes. 1-detaching base from hanging feeder, 2-cleaning with water wand, 3-shoveling feces, 4spreading rice hulls, 5-attaching base to hanging feeder, 6-unloading a box of chicks, 7-releasing chicks, 8-inspecting chickens, 9-loading chickens into crates, N-neutral, B-bend, T-twist, l-invisible; the segments are defined in Table 2. The percentage represents the ratio of the cumulative time for which each segment is used in the posture to the sampling time.

TABLE 7. Common Individual Finger Postures

\begin{tabular}{lccccccccccc}
\hline & \multicolumn{10}{c}{ Operations } \\
\cline { 2 - 13 } Fingers & Overall & $\mathbf{1}$ & $\mathbf{2}$ & $\mathbf{3}$ & $\mathbf{4}$ & $\mathbf{5}$ & $\mathbf{6}$ & $\mathbf{7}$ & $\mathbf{8}$ & $\mathbf{9}$ \\
\hline Right & $5 \mathrm{~W}$ & $\mathrm{I}$ & $5 \mathrm{~W}$ & $5 \mathrm{~W}$ & $5 \mathrm{~W}$ & $3 \mathrm{P}$ & $5 \mathrm{~W}$ & $5 \mathrm{~W}$ & $\mathrm{R}$ & $5 \mathrm{~W}$ \\
$\%$ & 58.1 & 79.9 & 100 & 100 & 100 & 68.3 & 68.5 & 74.2 & 100 & 57.6 \\
Left & $5 \mathrm{~W}$ & $5 \mathrm{~W}$ & $5 \mathrm{~W}$ & $5 \mathrm{~W}$ & $5 \mathrm{~W}$ & $5 \mathrm{~W}$ & $\mathrm{R}$ & $5 \mathrm{~W}$ & $\mathrm{R}$ & $5 \mathrm{~W}$ \\
$\%$ & 69.7 & 95.5 & 100 & 100 & 100 & 93.5 & 51.5 & 89.6 & 100 & 63.3 \\
\hline
\end{tabular}

Notes. 1-detaching base from hanging feeder, 2-cleaning with water wand, 3-shoveling feces, 4spreading rice hulls, 5-attaching base to hanging feeder, 6 - unloading a box of chicks, 7 -releasing chicks, 8 -inspecting chickens, 9 -loading chickens into crates, 5W-5-finger wrap, l-invisible, 3P-3-figer pinch, $\mathrm{R}$-resting. The percentage represents the ratio of the cumulative time for which each segment is used in the posture to the sampling time. 


\section{DISCUSSION}

Many studies have demonstrated the relationship between awkward working postures and MSDs $[29,30,31]$. This study built the common simultaneous and individual posture profiles of the body segments and fingers in the operations on a poultry farm for broiler chickens. The profiles were used to determine awkward postures other than neutral for 14 body segments and fingers in detail, which the operations required the farmers to adopt for a certain amount of their working time.

The broiler farmers bent almost all body segments during most of their working time because most work was done manually with both arms, using a wand, a shovel, and a broom. The operations of (2) cleaning with water wand and (8) inspecting chickens seemed light in a poultry farm for broilers. The former required bending or twisting only 4 body segments (right upper arm, left upper arm, right hand, and left hand), but the farmer adopted those prolonged static postures for $100 \%$ of the working time when holding a water wand. The farmer in the latter operation also bent only 6 body segments to inspect the chickens while walking around the inside of the shed. In contrast, (1) detaching base from hanging feeder, (3) shoveling feces, (5) attaching base to hanging feeder, (6) unloading a box of chicks, and (7) releasing chicks could be regarded as heavy work because they had the farmers bend over 11 body segments in simultaneous body postures. The farmers squatted and moved ahead without standing for over $60 \%$ of the working time in (1) detaching base from hanging feeder and (5) attaching based to hanging feeder because the hanging feeders were close to the floor. The farmers also repeatedly bent their trunks for shoveling and handling boxes on the floor over $56 \%$ of the working time in (3) shoveling feces, (6) unloading a box of chicks, and (7) releasing chicks.

All five fingers wrapped around a material (power grip), coded $5 \mathrm{~W}$ in this study, were both common simultaneous and individual postures of the fingers in almost all operations in a poultry farm for broilers. The farmers used pinching postures with three fingers of the right hand (3-jaw pinch), coded 3P in this study, in (1) detaching base from hanging feeder and (5) attaching base to hanging feeder to handle nuts, though the right fingers were invisible on video in (1).

This study was done as an evaluation of a series of working postures with the concepts of common simultaneous and individual postures of body segments and fingers in almost all operations of poultry farming for broilers. Hwang et al. developed a classifications of both body segments and fingers and applied them to 11 operations of dairy farming [6]. Wang et al. also adopted the classifications to evaluate working postures in 18 operations in an electric iron assembly plant [28]. Considering these studies together, a common working posture of each body segment seems to depend on the characteristics of industries, such as task difficulty, tool, workplace design (working height and distance), work duration, and working method. Dairy farming generally required bending the upper body segments including the trunk but neutral postures of the lower body segments because of a long distance between the cow and the farmer and the repetitiveness of standing and walking a long distance. However, poultry farming required bending most body segments because the farmers often squatted in a confined shed due to a low working height. The workers in the assembly plant adopted bending postures of the lower arms and hands and a neutral posture of the trunk, standing by a conveyor platform for most of their working time. A power grip and then a threejaw pinch were consistently the common finger postures for all three studied industries. The workers in the industries used the broom, bucket, hook, powered screwdriver, shovel, sickle, spray gun, water wand, and wheelbarrow that all had cylindrical handles for a power grip. They also used bolts and nuts for a three-jaw pinch.

In conclusion, even though automation is important for the development of poultry farms, a good design of the working environment is also necessary to reduce exposure to hazard. To assess the working environment of the broiler farmer, this study investigated the working postures of 
stockmen in a poultry farm for broiler chickens from two perspectives: as simultaneous postures and individual postures. The most common simultaneous posture, which represented the posture of all segments in a single frame, would be useful in designing a workplace. The most common individual posture, which focused on one segment only, would be helpful in evaluating the physical workload of each body segment [6, 28]. On the basis of the results of this study, a redesign of the working environment and equipment to eliminate exposure to postural stress could be considered. A possible redesign solution would be to raise the working height for better working conditions on a broiler chicken farm. Finally, this study could be further improved by having more workers evaluated in diverse industries for generalization and by considering body segment angles rather than only four simple classifications.

\section{REFERENCES}

1. Nevala-Puranen N. Reduction of farmers' postural load during occupationally oriented medical rehabilitation. Appl Ergon. 1995;26:411-5.

2. Pinzke S. A computerized system for analyzing working postures in agriculture. Int J Ind Ergon. 1994;13:307-15.

3. Pinzke S. Observational methods for analyzing working postures in agriculture. J Agric Saf Health. 1997;3:169-94.

4. Ahonen E, Venäläinen JM, Könönen U, Klen T. The physical strain of dairy farming. Ergonomics. 1990;33:1549-55.

5. Gustafsson B, Pinzke S, Isberg PE. Musculoskeletal symptoms in Swedish dairy farmers. Swedish J Agric Res. 1994; 24:177-88.

6. Hwang J, Kong YK, Jung MC. Posture evaluations of tethering and loose-housing systems in dairy farms. Appl Ergon. 2010; 42:1-8.

7. Lundqvist $P$, Stål M, Pinzke S. Ergonomics of cow milking in Sweden. J Agromed. 1997;4:169-76.

8. Nevala-Puranen N, Kallionpää M, Ojanen K. Physical load and strain in parlor stall milking. Int J Ind Ergon. 1996; 18:277-82.
9. Perkiö-Mäkelä M, Hentilä H. Physical work strain of dairy farming in loosehousing barns. Int J Ind Ergon. 2005;35: 57-65.

10. Pinzke S, Stål M, Hansson GÅ. Physical workload on upper extremities in various operations during machine milking. Ann Agric Environ Med. 2001;8:63-70.

11. Stål M, Moritz U, Gustafsson B, Johnsson B. Milking is a high-risk job for young females. Scand J Rehab Med. 1996;28:95-104.

12. Stål M, Hansson GÅ, Moritz U. Wrist positions and movements as possible risk factors during machine milking. Appl Ergon. 1999;30:527-33.

13. Stål M, Hansson GÅ, Moritz U. Upper extremities muscular load during machine milking. Int J Ind Ergon. 2000;26:9-17.

14. Christensen $H$, Vinzents $P$, Nielsen $B H$, Finsen L, Pedersen MB, Sjøgaard G. Occupational exposures and health among Danish farmers working in swine confinement buildings. Int J Ind Ergon. 1992;10:265-73.

15. Geng Q, Torén A. Mobile and stationary systems for organic pigs-working environment. In: Köpke U, Niggli U, Neuhoff D, Cornish P, Lockeretz W, Willer H, editors. Researching sustainable systems. Adelaide, Australia: International Society of Organic Agriculture Research; 2005. p. 246-9.

16. Stål M, Englund JE. Gender difference in prevalence of upper extremity musculoskeletal symptoms among Swedish pig farmers. J Agric Saf Health. 2005;11: 7-17.

17. Lee KS, Lee SH. Musculoskeletal stress disorder problems at a chicken farm. J Korean Soc Saf. 2007;22:90-5.

18. Lundqvist $P$. A new type of poultry house: ergonomical problems and accident risks. In: McDuffice $\mathrm{HH}$, Dosman JA, Semchuk KM, Olenchock SA, Senthilselvan A, editors. Agricultural health and safety-workplace, environment, sustainability. Boca Raton, FL, USA: CRC Press; 1995. p. 333-8.

19. Scott GB, Lambe NR. Working practices in a perchery system using the OVAKO working posture analysing system (OWAS). Appl Ergon. 1996;27:281-4. 
20. De A, Sen R. A work measurement method for application in Indian agriculture. Int J Ind Ergon. 1992;10:285-92.

21. Sakakibara H, Miyao M, Kondo T, Yamada S, Nakagawa T, Kobayashi F. Relation between overhead work and complaints of pear and apple orchard workers. Ergonomics. 1987;30:805-15.

22. Karhu O, Kansi P, Kuorinka I. Correcting working postures in industry: a practical method for analysis. Appl Ergon. 1977;8: 199-201.

23. Waters TR, Putz-Anderson V, Garg A, Fine LJ. Revised NIOSH equation for the design and evaluation of manual lifting tasks. Ergonomics. 1993;36:749-76.

24. Hignett S, McAtamney L. Rapid entire body assessment (REBA). Appl Ergon. 2000;31:201-5.

25. Armstrong TJ, Foulke JA, Joseph BS, Goldstein SA. Investigation of cumulative trauma disorders in a poultry processing plant. Am Ind Hyg Assoc J. 1982;43: 103-16.
26. Keyserling WM. A computer-aided system to evaluate postural stress in the workplace. Am Ind Hyg Assoc J. 1986;47:641-9.

27. McAtamney L, Corlett EN. RULA: a survey method for the investigation of work-related upper limb disorders. Appl Ergon. 1993;24:91-9.

28. Wang H, Hwang J, Lee KS, Kwag JS, Jang JS, Jung MC. Upper body and finger posture evaluations at an electric iron assembly plant. Human Factors and Ergonomics in Manufacturing \& Service Industries. 2012 (dx.doi.org/doi:10.1002/ hfm.20362).

29. Andersson GBJ, Örtengren R, Herberts P. Quantitative electromyographic studies of back muscle activity related to posture and loading. Orthop Clin North Am. 1977;8: 85-96.

30. Hagberg M. Local shoulder muscular strain - symptoms and disorders. J Human Ergol. 1982;11:99-108.

31. Magora A. Investigation of the relation between low back pain and occupation. Ind Med. 1972;41:5-9. 